\title{
ANÁLISE SOCIOESPACIAL DAS ÁREAS VERDES EM FLORIANÓPOLIS
}

\section{SOCIOSPATIAL ANALYSIS OF GREEN SPACES IN FLORIANÓPOLIS}

\section{German Gregório Monterrosa Ayala Filha (UFSC); \\ Alina Gonçalves Santiago, Dra. (UFSC); Vanessa Casarin, Dra. (UFSC)}

\author{
Palavras Chave \\ Áreas verdes; Análise socioespacial; Sistemas de informação geográfica; Plano diretor de Florianópolis
}

\section{Key Words}

Green spaces; Sociospatial analysis; Geographic information system; Florianópolis master plan.

\section{RESUMO}

Áreas verdes e espaços livres no meio urbano desempenham funções sociais, estéticas, ecológicas, educativas e estão diretamente relacionadas à qualificação de uma cidade. O poder público deve instalar, administrar e garantir a manutenção e acessibilidade dessas áreas, de modo que, todos os habitantes tenham diretos iguais em usufruir desses espaços. Sendo assim, este estudo discute como a distribuição populacional e de renda em Florianópolis (SC), relaciona-se com a disposição de áreas públicas de lazer. Optou-se como método de investigação uma análise exploratória e quantitativa, por meio de Sistemas de Informação Geográfica, das Áreas Verdes Livres (AVL) delimitadas pelo Zoneamento municipal. Como principal resultado, evidenciou-se que há uma distribuição desequilibrada de AVL e há uma correlação dessa distribuição com a concentração de renda no município. Secundariamente, este estudo motiva uma revisão da legislação municipal vigente, a adequação das bases cartográficas fornecidas pelo poder público e a disponibilização de notas metodológicas para a sua definição.

\section{ABSTRACT}

Green areas and open spaces in urban environment fulfill functions that are social, aesthetic, ecological, educational and are directly related to the qualification of a city. Public Policies must install, manage and ensure mainteance and accessibility for these areas, in a way that, all inhabitants have equal rights to enjoy these spaces. Thus, this study discusses how the population and income distribution in Florianópolis (SC), is related to the provision of public leisure areas. We chose the investigational method as an exploratory and quantitative analysis, through Geographic Information System (GIS), of the Open Green Spaces (OGS) delimited by the Municipal zoning. As a main result, it was evidenced that there is an unbalanced distribution of OGS and there is a correlation of this distribution with concentration of income in the municipality. Secondly, this study motivates a revision of current municipal legislation, adequacy of cartographic database provided by city hall and the availability of methodological notes for its definition. 


\section{INTRODUÇÃO}

O atual cenário de intensificada urbanização repercute em alterações na forma como se dá o relacionamento do ser humano com o meio ambiente e com a paisagem, além disso, cidades têm se tornado ambientalmente inadequadas, seja pelo déficit de arborização, áreas livres e espaços de lazer ou pela poluição e diversos outros fatores decorrentes da ocupação antrópica, do mercado imobiliário e da ineficácia nas políticas de ordenamento territorial.

Bartalini (1986) afirma que áreas verdes e espaços livres no meio urbano desempenham as funções: visuais ou paisagísticas, recreativas e ambientais. Essas funções não são excludentes e idealmente deveriam estar interligadas. Goettems e Bueno (2016) complementam que, a qualificação da cidade está diretamente relacionada com esses espaços.

O poder público deve instalar, administrar e garantir a manutenção e acessibilidade de áreas verdes e espaços públicos de lazer, de modo que, todos os habitantes tenham direitos iguais em usufruir desses espaços. Isso significa que, a distribuição dessas áreas deve ser compatível com a demanda de usuários e os deslocamentos desses usuários até esses espaços devem ser facilitados.

Segundo Villaça (2001), normalmente nas cidades brasileiras existe áreas mais bem servidas de equipamentos urbanos. Entretanto, para o autor, nessas áreas reside uma minoria que desfruta desses equipamentos; resultados do trabalho social. Refere que a maioria periférica permanece excluída da possibilidade de usufruir desses equipamentos.

A partir dessa problemática, este trabalho objetiva: Entender como a distribuição populacional e de renda em Florianópolis, capital do estado de Santa Catarina, relacionam-se com a disposição de áreas públicas de lazer.

Optou-se como metodologia de investigação, a análise de áreas delimitadas no zoneamento de Florianópolis por meio do uso de Sistemas de Informação Geográfica (SIG). A ferramenta SIG permite dimensionar esses espaços e avaliar a sua distribuição espacial, considerando a densidade populacional e a renda média para cada bairro da cidade. Parte-se da hipótese de que essas áreas não estão distribuídas de forma equilibrada.

O Plano Diretor de Florianópolis (Lei Complementar n 482/14) instituiu Áreas Verdes de Lazer (AVL) em seu zoneamento que, segundo o regimento da Lei, são espaços urbanos ao ar livre de uso e domínio público que se destinam à prática de atividades recreativas, privilegiando quando possível a criação ou a preservação da cobertura vegetal (FLORIANÓPOLIS, 2014).

Entende-se que critérios meramente quantitativos não satisfazem, é necessário saber para que servem, onde se localizam e como estão distribuídos esses espaços. Da mesma forma, grandes extensões de áreas verdes de interesse ambiental, mas sem qualquer possibilidade de uso, ou ainda, sem acessibilidade, dificilmente ganharão um significado coletivo e estarão mais facilmente expostas a pressões especulativas (BARTALINI, 1986).

Apesar da reserva atentada pelo autor supracitado, esse estudo pretende fazer um diagnóstico inicial dessas áreas em uma escala macro para que futuramente, permita-se uma avaliação qualitativa em escalas menores. Entende-se também que, as definições e estudos de Bartalini (1986), mesmo que datem de mais de 30 anos atrás, permanecem extremamente pertinentes à problemática de análise no atual cenário brasileiro.

\section{2. ÁREAS VERDES LIVRES}

Para adequada compreensão de, como se chegou à atual relação da sociedade capitalista com a paisagem, a natureza, e espaços livres, sugerimos a leitura dos trabaIhos de Leite (1992) e Arantes (1994), pois não exploraremos a forma como se da essa relação neste trabalho.

Diante das diversas conceituações de espaço livre, espaços públicos e áreas verdes, este estudo parte das definições de Magnoli (1982), Morero, Dos Santos e Fidalgo (2007) e Custódio et al. (2011) em que, uma área verde livre é um espaço não edificado ao redor de edificações, engloba locais onde predomina a vegetação, sua distribuição deve servir a toda população, sem privilegiar qualquer classe social e deve atingir as necessidades reais e os anseios da população para o lazer.

Segundo Bargos e Matias (2011), esses espaços desempenham funções sociais, estéticas, ecológicas, educativas e psicológicas na malha urbana. Essas áreas possibilitam o lazer, diversificam e embelezam a paisagem construída da cidade, provêm melhorias na qualidade do ar, água e solo, oferecem ambiente para atividades educativas e possibilitam atividades de relaxamento.

O Art. 57 e 58 da Lei do Plano Diretor Municipal de Florianópolis define AVL como:

Espaços urbanos ao ar livre de uso e domínio público que se destinam à prática de lazer e recreação, privilegiando quando possível a criação ou preservação da cobertura vegetal. Nas AVL será permitida apenas a construção de equipamentos de apoio ao lazer ao ar livre, como playgrounds, sanitários, vestiários, quiosques e dependências necessárias aos serviços de segurança e conservação da área (FLORIANÓPOLIS, 2014). 
Ainda segundo a Lei municipal, Art 90, parágrafos $3^{\circ} \mathrm{e}$ 50, para os novos parcelamentos:

As normas gerais do parcelamento do solo urbano em Florianópolis dispõem que as AVL deverão ter superfície contínua de, no mínimo dois mil metros quadrados e deverão estar localizadas junto às vias principais ou de maior acesso possivel, previstas pelo loteamento e aprovadas pelo Instituto de Planejamento Urbano de Florianópolis (IPUF) (FLORIANÓPOLIS, 2014 - grifos dos autores).

Aqui se revelam aspectos importantes, existe uma preocupação do poder público em estabelecer que as novas AVL parceladas sejam contínuas, acessiveis e integradas à malha urbana. Além do que, devem dispor de área mínima de dois mil metros quadrados. Na Seção 5 verificaremos que significativa parte das AVL instituídas pelo zoneamento municipal não atendem a essas exigências.

\section{MUNICÍPIO DE FLORIANÓPOLIS}

Florianópolis é a capital do estado de Santa Catarina e possui uma população de 421.240 habitantes (IBGE, 2010), distribuídos pelos $436 \mathrm{~km}^{2}$ de área que se dividem nas porções continental e insular (Figura 1). A região metropolitana da grande Florianópolis abriga mais de 1 milhão de habitantes, sendo que $87 \%$ dela se encontra no núcleo conurbado da região, compreendendo os municípios de Florianópolis, São José, Biguaçu e Palhoça (SANTIAGO et al., 2014).

Figura 01: Município de Florianópolis. Florianópolis está marcada em marrom, apresenta-se sua localização em relação ao território brasileiro e divide-se o município em bairros.

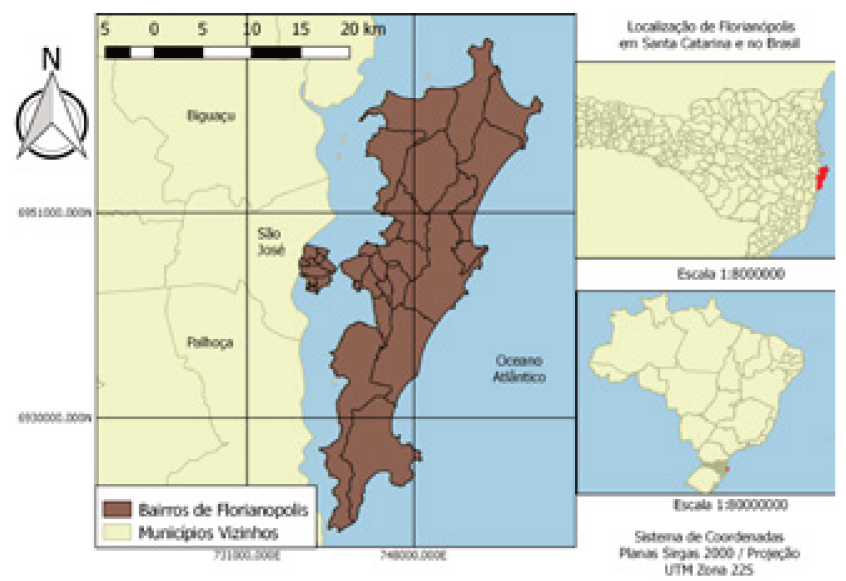

Fonte: Mapa produzido por autores em 2017 sobre bases cartográficas do IBGE e da Prefeitura Municipal de Florianópolis (PMF).
Segundo Santiago et al. (2014), os espaços livres urbanos destinados à recreação e áreas verdes de lazer não representam $1 \%$ da área total do município, essa carência seria justificada pela presença de orlas marítimas e lacustres, que são consideradas Áreas de Preservação Permanente (APP) pelo zoneamento do Plano Diretor de Florianópolis. As praias, os calçadões e o mar são considerados os principais espaços públicos recreativos da cidade. A principal problemática é a distribuição desses espaços, tendo em vista que ela não atende à demanda populacional e social (MACEDO, 2012).

\section{MATERIAIS E ASPECTOS}

\subsection{Metodológicos}

Este estudo tem caráter quantitativo e exploratório, foram calculados Índices de Área Verde Livre por Habitante (IAVL) para cada bairro de Florianópolis, objetivando quantificar a distribuição das AVL no município. A partir dos IAVL, são apresentados mapas temáticos e tabelas que comparam a distribuição dessas áreas com a distribuição de renda. Cunha (2003) preconiza que o IPUF admite como ideal, o índice de $4,5 \mathrm{~m}^{2}$ de espaço livre para cada habitante, portanto esse valor foi utilizado como referência. Os IAVL foram calculados da seguinte forma (Equação 1):

As bases cartográficas que contém os limites de cada bairro estão disponíveis na página virtual de Geoprocessamento Corporativo da Prefeitura de Florianópolis. As AVL do município também podem ser verificadas na mesma página, entretanto, os arquivos editáveis utilizados neste estudo precisaram ser solicitados ao IPUF, órgão da Prefeitura Municipal de Florianópolis (PMF).

Os dados alfanuméricos utilizados de população e renda para cada bairro foram extraídos do censo demográfico do Instituto Brasileiro de Geografia e Estatística (IBGE) de 2010, agregados por setor censitário com os resultados do universo. Entende-se que a estratificação de renda não satisfaz completamente como parâmetro para a definição de classe social, embora Giddens (1975) alerte que não se pode escapar completamente desse tipo de representação.

O tratamento e classificação das bases cartográficas e a geração dos mapas temáticos se deram em ambiente SIG, por meio do software livre QGIS 2.18.14. 


\section{RESULTADOS}

Para um diagnóstico inicial da distribuição das AVL em Florianópolis, foi elaborado um mapa da densidade habitacional de cada bairro e a localização geográfica de todas as AVL (Figura 2). Verifica-se que não necessariamente as áreas mais habitadas são as que concentram o maior número de AVL.

Figura 02: Mapa da localização das AVL x Densidade populacional dos bairros de Florianópolis. As AVL estão representadas em verde e a densidade populacional em escalas de vermelho, sendo que, quanto mais escuro, mais povoado é o bairro. O mapa possibilita verificar que as AVL estão mais concentradas na região central de Florianópolis e não necessariamente onde há maior número de habitantes.

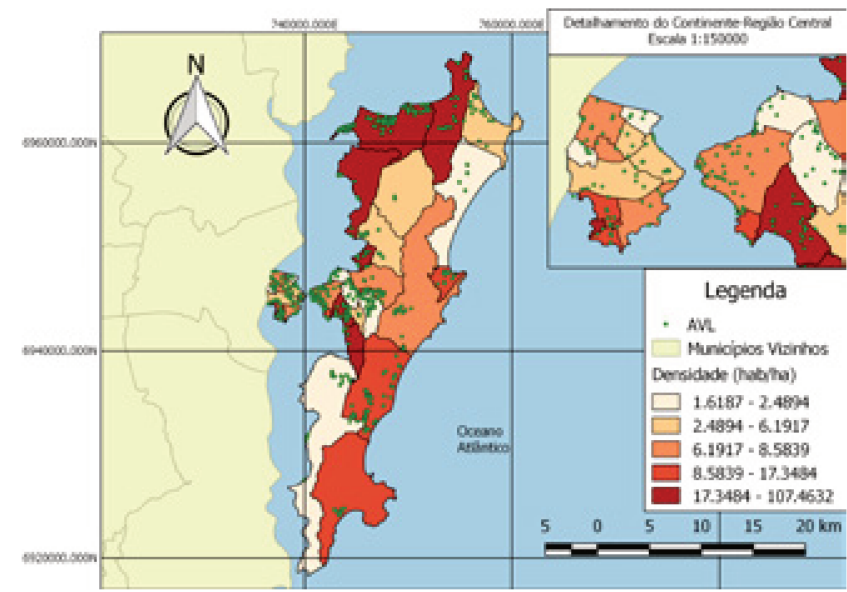

Fonte: Mapa produzido por autores em 2017 sobre polígonos da PMFe IBGE e dados alfanuméricos do IBGE.

A Tabela 1 sintetiza os resultados gerais encontrados, os bairros foram listados de forma em que os IAVL estão organizados em ordem crescente. Baseando-se na área de AVL do município inteiro e em sua população total, obteve-se um índice de áreas verdes livres por habitante de aproximadamente $12,92 \mathrm{~m}^{2} /$ habitante, que pode ser interpretado como oferta suficiente e até adequada desses espaços.

Entretanto, quando reduzida a escala de análise, para uma regionalização por bairros, há 10 bairros que possuem um IAVL inferior a $4,5 \mathrm{~m}^{2} / \mathrm{hab}$, contrariando a própria recomendação do IPUF. Tais resultados confirmam a hipótese da que há um desequilíbrio na distribuição das AVL.
Tabela 01: Relação entre bairros, AVL, renda média, população, área $\mid A V L$, sintetizando os resultados obtidos, a sexta coluna está ordenada em ordem crescente.

\begin{tabular}{|c|c|c|c|c|c|c|}
\hline Bume & ANL (m) & $\begin{array}{l}\text { Antes Madia } \\
\text { (HS) }\end{array}$ & Populacis: & Aret (ha) & $\underset{t=1 \text { Lab }}{\text { WNL }}$ & $\begin{array}{l}\text { Denaldede } \\
\text { (Wab/ha) }\end{array}$ \\
\hline $\begin{array}{l}\text { CORARCO } \\
\text { GRANDE }\end{array}$ & 17895 & 4452 & 11031 & 664900 & 1,6189 & 165 \\
\hline MONTE CRISTO & 2473,46 & 1109 & 1317า & 202000 & 1,8973 & 222,22 \\
\hline AGRONOMCA & $315150 y$ & $m \pi$ & 16058 & $1017 m 8$ & 1.9636 & 81.18 \\
\hline BALNEARIO & 1267394 & 3540 & 6296 & 707614 & 2,013 & Bsos \\
\hline $\begin{array}{c}\text { RIBEIRAO DA } \\
\text { ILA }\end{array}$ & 51884,75 & 1645 & 23364 & sapanos & 22207 & 4,41 \\
\hline 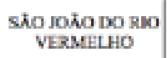 & 3411,67 & 1309 & 16984 & 315718 & 2.3728 & 4.56 \\
\hline TRENDADE & 4sedion & 2772 & 192,42 & 952757 & 2378 & 3,6 \\
\hline MNTANAL. & 15290.161 & mos & 596 & JiMan & 24.44 & 2551 \\
\hline CANTO & 29272.236 & 387 & 6084 & 72011 & $3+18$ & 96,72 \\
\hline 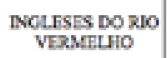 & 10024,45 & $2 \% 1$ & 2924 & $19+4059$ & 3,7928 & 14,02 \\
\hline RATONES & 7525 & 1580 & 1590 & 32612587 & 4,7327 & 0,49 \\
\hline SACOGRAKDE & 73142.86 & 2137 & 18506 & 1615269 & 50422 & 8,06 \\
\hline CAPOERAS & \$कos. 151 & 2151 & 1902 & 2836122 & 53120 & 6735 \\
\hline ISTRIITO & \$145i,111 & tons & SLAB & imatis & 6.14i3 & 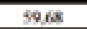 \\
\hline $\begin{array}{l}\text { AADBLM } \\
\text { ATLANTCO }\end{array}$ & Tow236 & 208 & 12628 & 183541 & 6005 & $68 \%$ \\
\hline COLONINHA & 33824357 & 2121 & $\$ 179$ & 55009 & 65311 & $97,8]$ \\
\hline COQUERTOS & ssobsons & 3400 & 1306 & 17961318 & 69411 & 77,65 \\
\hline CNTRO & 711615,514 & 4775 & 45 & gatolit & 6.951 & A2, $\mathrm{ki}$ \\
\hline $\begin{array}{l}\text { LAOOA DA } \\
\text { COAcacho }\end{array}$ & 25761.100 & 2016 & $\omega n$ & stowes & $\operatorname{sen} 6$ & 134 \\
\hline IIACORLBI & 130415,54 & 360 & Ilows & 12845954 & 8.1008 & 1253 \\
\hline PRSTANO DOSUT & stost,411 & $1 \% 4$ & 6773 & 476 stes & 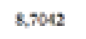 & 1,41 \\
\hline SosE MENDES & 390,373 & 1970 & $3 x s$ & stoust & 102471 & 600 \\
\hline ABRANo & 8)597,9es & 2005 & 645 & subtos & 12.159 & 7868 \\
\hline riouscu & 4916,247 & 4455 & 254 & 464045 & $\mid 1,0,0)$ & 3568 \\
\hline CAMPCIIR & 356597,564 & 2397 & $n s n_{2}$ & 35ito6sil & 15,7005 & 6,43 \\
\hline EARPADALACOA & som,sent & 1636 & $5 m$ & 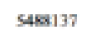 & 160561 & 9,83 \\
\hline sAkTAMSICA & 3130,45 & $4 m$ & 2128 & 591135 & 16978 & 3582 \\
\hline $\begin{array}{l}\text { CACHOLEA DO } \\
\text { DOU HISLS }\end{array}$ & 21130,00 & 地国 & $11 \%$ & manson & 17,00 & 3,88 \\
\hline DOM̄O PALOO & 115747,500 & 4006 & 5244 & 2824640 & 22,0724 & {$[1,57$} \\
\hline BOM ABSACDO & 5413467 & 4161 & 1900 & |b04II & 27,407 & 109,75 \\
\hline $\begin{array}{c}\text { SIO AWTÓNO DE } \\
\text { LISHOA }\end{array}$ & $\operatorname{sen} 20 \pi, 6$ & 365 & 2123 & 21679099 & 32,1284 & 0,98 \\
\hline CANASVIETRS & $\sin 10.447$ & 3008 & 15717 & xasose & 56,7272 & 5,36 \\
\hline $\begin{array}{l}\text { SACO Dos } \\
\text { LMOOS }\end{array}$ & 20117,72 & 2192 & 15140 & w2w & 67,379 & 36,59 \\
\hline $\begin{array}{l}\text { COSTEIRADO } \\
\text { PIRAULAP }\end{array}$ & 1654321,06 & 176 & shis & 6417136 & 107,4632 & 15,29 \\
\hline
\end{tabular}

Fonte: produzido por autores em 2017 sobre dados do IBGE e da PMF.

Os bairros que obtiveram os IAVL inferiores a 4,5 $\mathrm{m}^{2} / \mathrm{hab}$ apresentam uma renda média de $\mathrm{R} \$ 500$ reais $(17,65 \%)$ inferior à média de renda dos bairros que possuem um IAVL acima de 20 $\mathrm{m}^{2} / \mathrm{hab}$. Um segundo aspecto notável é que os bairros mais povoados não são necessariamente os que oferecem mais espaços livres de lazer, os 10 bairros menos servidos de AVL possuem uma densidade $16,84 \%$ maior do que os cinco mais servidos.

Algumas áreas do município são favorecidas em equipamentos públicos de lazer e há uma correlação dessa distribuição, mesmo que estreita, com a concentração de renda dos munícipes. Esses resultados corroboram aspectos sugeridos pela literatura previamente revisada. 
Figura 03: Mapas de IAVL e da renda média por chefe familiar em Florianópolis. Os $\mid A V L$ e as rendas médias estão representadas em tons de verde, sendo que, os mais escuros representam maiores IAV $L$ e maior renda. Evidencia-se que alguns dos bairros com menor rendimento familiar são também os que dispõe de menos AVL.
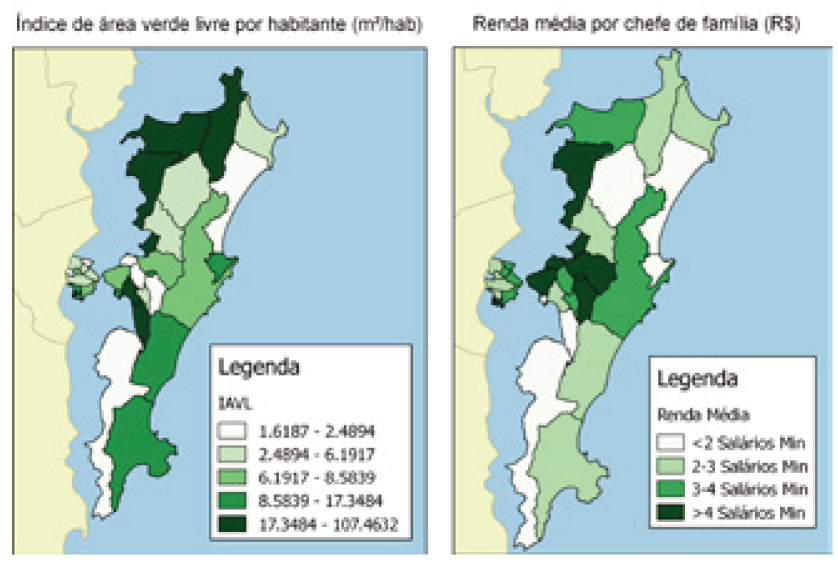

Fonte: Mapa produzido por autores em 2017, utilizando dados alfanuméricos do IBGE e mapas de bairros e uso do solo da PMF.

Uma análise mais detalhada das AVL demarcadas pelo IPUF mostra que algumas áreas delimitadas não oferecem qualquer infraestrutura ou acessibilidade. Existem áreas consideradas AVL que não estão integradas à rede viária ou que nem mesmo se inserem na malha urbana. A Figura 4 compara por meio de imagens de satélite do Google, AVL demarcadas na região central de Florianópolis, próximas à ponte Hercílio Luz e AVL delimitadas na região sul da ilha.

O detalhamento dessas áreas incita uma revisão das zonas de AVL elaboradas para o Plano Diretor de Florianópolis, o texto da Lei dedica insuficiente descrição desses espaços, constata-se também a falta de notas metodológicas disponibilizadas pela Prefeitura que sejam referentes à demarcação dessas áreas. O mapeamento elaborado como suporte ao Plano Diretor não satisfaz as necessidades do planejamento, visto que, algumas áreas consideradas AVL pelo IPUF não apresentam características suficientes para serem apropriadas pelos habitantes do município.
Figura 04: Detalhamento de AVL demarcadas na região central e sul de Florianópolis. Evidencia-se que as áreas demarcadas na região central, no primeiro mapa (de cima), de fato representam $A V L$ e coincidem com sua descrição jurídica. As áreas demarcadas na região periférica, no segundo mapa (de baixo), não são espaços que permitem uso e apropriação e foram mapeados erroneamente no zoneamento municipal.

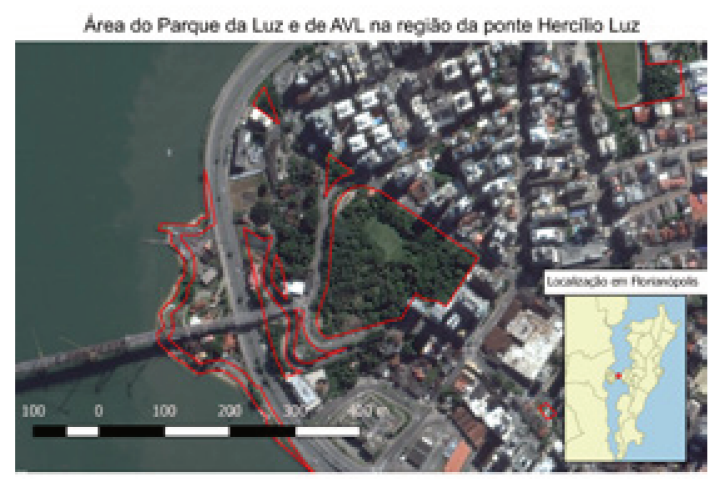

Area demarcada como AVL nús inegrada a malha urbant

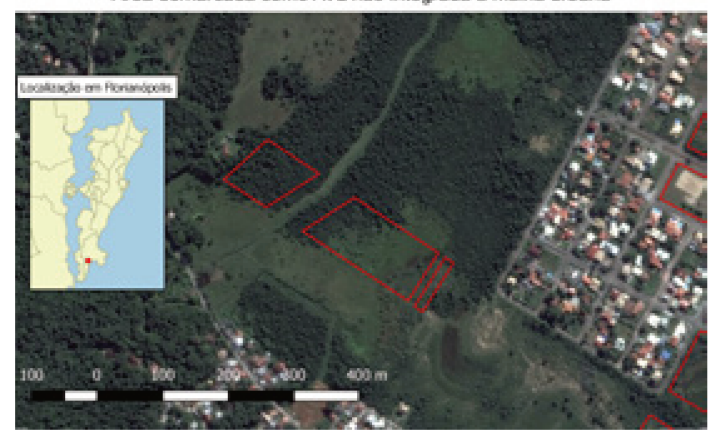

Fonte: Mapa produzido por autores em 2017 sobre polígonos da PMF e imagens do Google.

Considerando que a legislação municipal exige que para novos parcelamentos de $\mathrm{AVL}$, a área mínima deve ser de pelo menos dois mil metros quadrados, verificamos quais das AVL existentes se adequam a esta restrição (Figura 5). 
Figura 05:AVL com áreas superiores e inferiores a 2.000 m. As AVL com área igual ou superior a $2.000 \mathrm{~m}$ estão marcadas em verde e as com área inferior em vermelho. Verifica-se que significante parte das AVL de Florianópolis não atende às novas exigências da Lei do Plano Diretor Municipal.

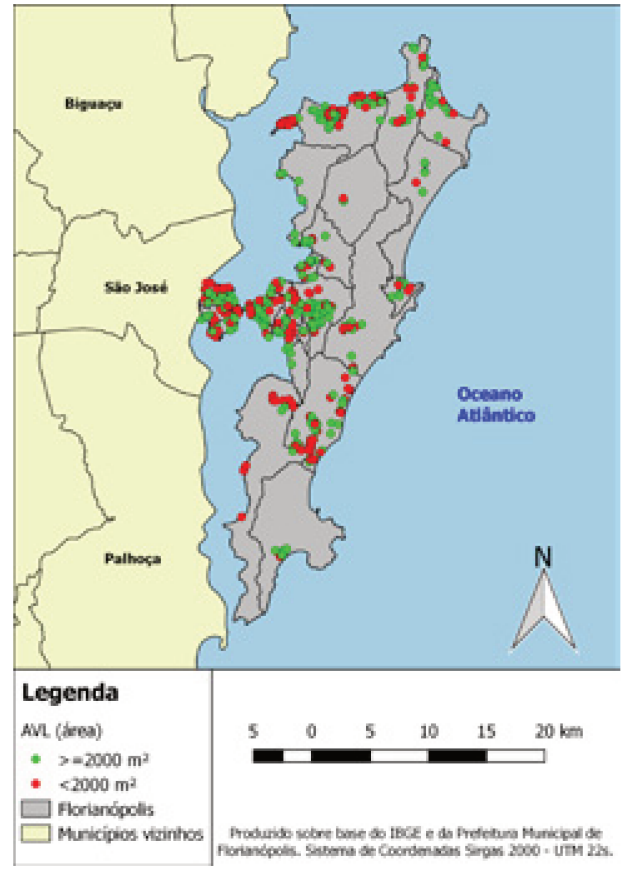

Fonte: Mapa produzido por autores em 2018 sobre base cartográfica do IBGE e da PMF.

Em um total de $539 \mathrm{AVL}$ demarcadas no zoneamento municipal, 264 possuem área inferior a dois mil metros quadrados, contrariando as novas exigências para parcelamento do solo na Lei do Plano Diretor vigente.

\section{CONSIDERAÇÕESFINAISERECOMENDAÇÕES}

Este trabalho analisa preliminarmente as AVL em Florianópolis e não pretende esgotar a temática, pelo contrário. Sugere-se uma revisão e um maior detalhamento da legislação municipal referente a espaços livres de lazer, assim como a retificação das bases cartográficas disponibilizadas pelo poder público.

Como resultados principais, confirma-se que há uma desequilibrada oferta de áreas verdes e espaços livres no município e as análises sugerem que há uma relação da localização desses espaços no município com a renda dos que habitam suas proximidades.

Para o caso de Florianópolis, uma cidade litorânea, existe a apropriação de espaços considerados APP para o uso recreativo, que deve ser considerada em análises futuras. Um desafio metodológico para esse caso seria propor uma forma de inserir as áreas de orlas marítimas e lacustres no cálculo de indicadores, visto que, as orlas têm características diferenciadas e normalmente não está integrada à malha urbana da mesma forma que as
AVL. Um segundo aspecto a se considerar são os Campi Universitários que também são espaços públicos que eventualmente são utilizados para lazer.

Com a adequação das AVL e o acréscimo das áreas públicas de orla aos espaços livres de recreação, espera-se que seja possível entender a distribuição desses espaços com maior confiabilidade. Factualmente, é possível que exista maior disparidade de renda relacionada à disposição dessas áreas.

Além disso, considerando que apenas critérios quantitativos não retratam a realidade municipal com exatidão, recomenda-se uma avaliação qualitativa in loco das referidas áreas. É necessário examinar suas particularidades, e investigar como se dá a apropriação desses espaços e discriminar os usuários que usufruem desses espaços.

Para finalizar, dois questionamentos principais podem se levantados. O primeiro, de que forma a Lei do plano diretor contribui para a democratização e apropriação de espaços livres de lazer? Considerando que parte das AVL existentes está em desacordo com a legislação municipal. E o segundo, qual é, e como se relaciona com aspectos socioeconômicos, a distribuição espacial dessas áreas se considerarmos todo o espaço intraurbano de Florianópolis? Se avaliarmos todo o território conurbado que compõe a região metropolitana da capital (municípios de Florianópolis, Biguaçu, São José e Palhoça).

\section{REFERÊNCIAS}

ARANTES, Antonio Augusto. A guerra dos lugares: sobre fronteiras simbólicas e liminaridades do espaço urbano. Revista de Patrimônio Histórico e Artístico Nacional. v. 2 p. 190-203, 1994.

BARGOS, Danúbia Caporusso; MATIAS, Lindon Fonseca. Áreas verdes urbanas: um estudo de revisão e proposta conceitual. Revista da Sociedade Brasileira de Arborização Urbana. São Paulo, v. 6, n. 3, p. 172-188, 2011.

BARTALINI, Vladimir. Áreas Verdes e Espaços Livres Urbanos. In: MACEDO, S. S. Paisagem e Ambiente: ensaios. São Paulo, n. 1 e 2, p.49-54, 1986.

CUNHA, Rita Dione Araújo. Os espaços públicos abertos e as leis de uso e ocupação do solo: uma questão de qualidade para ambientes sustentáveis. In: III Encontro Nacional sobre Edificações e Comunidades Sustentáveis, 2003, São Carlos, SP. Anais do III ENECS. São Carlos, SP, 2003. 
CUSTÓDIO, Vanderli. et al. Espaços Livres Públicos nas Cidades Brasileiras. Revista Geográfica da América Central. Costa Rica, número especial EGAL, p.1-31, 2011.

FLORIANÓPOLIS. Lei complementar no 482 de 17 de janeiro de 2014. Institui o Plano Diretor de urbanismo do município de Florianópolis que dispõe sobre a política de desenvolvimento urbano, o plano de uso e ocupação do solo, os instrumentos urbanísticos e o sistema de gestão. Prefeitura de Florianópolis, Florianópolis, SC, 17 jan. 2014. Disponível em: <http://www.pmf.sc.gov.br/arquivos/arquivos/pdf/04_02_2014_12.01.39.ae8afdb369c91e13ca6efcc14b25e055.pdf>. Acesso em: 04 nov 2017.

GIDDENS, Anthony. A estrutura de classes nas sociedades avançadas. Rio de Janeiro: Zahar, 1975.

GOETTEMS, Renata Franceschet.; BUENO, Ayrton Porto. Uso e apropriação dos espaços públicos de lazer (praças) de Joinville/SC. In: VII Seminário Internacional de Investigación en Urbanismo, 2016, Barcelona. Anais... Barcelona, 2016.

INSTITUTO BRASILEIRO DE GEOGRAFIA E ESTATÍSTICA. Censo Demográfico 2010 - agregados por setores censitários dos resultados do universo - Santa Catarina. Rio de Janeiro: IBGE, 2010. Disponível em: <http://mapas.ibge. gov.br/bases-e-referenciais/bases-cartograficas/malhas-digitais>. Acesso em: 18 nov. 2016.

LEITE, Maria Angela Faggin Pereira. A paisagem, a natureza e a natureza das atitudes do homem. Paisagem e ambiente: ensaios. São Paulo, n. 4, p. 45-66, 1992.

MACEDO, Silvio Soares et al. Os sistemas de Espaços Livres e a constituição da esfera pública contemporânea no Brasil. Paisagem e Ambiente: ensaios. São Paulo, n. 30, p. 137-172, 2012.

MAGNOLI, Miranda Maria Esmeralda Martinelli. Espaços Livres e Urbanização. Tese (Livre-docência) Faculdade de Arquitetura e Urbanismo, Universidade de São Paulo, 1982.

MORERO, Andrea Maria; DOS SANTOS, Rozely Ferreira; FIDALGO, Elaine Cristina Cardoso. Planejamento ambiental de áreas verdes: estudo de caso de Campinas-SP. Revista do Instituto Florestal. v. 19, n. 1, p. 19-30, 2007.
SANTIAGO, Alina Gonçalves et al. Espaços livres e forma urbana: interpretando características e conflitos em Florianópolis (SC). Paisagem e Ambiente: ensaios. São Paulo, n. 33, p. 49-66, 2014.

VILLAÇA, Flávio. Espaço Intra-urbano no Brasil. São Paulo: Editora Studio Nobel, 2001. 